\title{
ADENOSINE DEAMINASE (ADA) IN TUBERCULOUS MENINGITIS
}

\author{
DEVENDRA NATH SKARAR ${ }^{1}$, MD. ISMAIL HOSSAIN ${ }^{2}$, A K M SHOAB ${ }^{3}$, ROBED AMIN $^{4}$ \\ Received: 01 December 2013 \\ Accepted: 19 June 2014
}

\section{Introduction}

Tuberculosis is one of the leading causes of mortality and morbidity in developing countries. The WHO reports puts to the record that globally, approximately 16 million people are suffering from active TB with an estimated 8.5 million developing active TB each year, resulting in approximately 2 million deaths. (WHO reports 2003).Tuberculous meningitis (TBM) is a common infectious disease of the central nervous system in developing countries. Early diagnosis and treatment with chemotherapy and active management of the complications are of great importance to prevent the irreversible neurologic sequel and death. Delay in diagnosis and so in the start of effective treatment results in poor prognosis and sequalae in up to $25 \%$ of cases (Garcia 1999). A definitive diagnosis of tuberculous meningitis depends on identifying Mycobacterium tuberculosis in the cerebrospinal fluid (CSF) by direct staining or culture. However, the diagnostic yield of CSF smears and cultures has been very low (Chotmongkol et al, 1996), and mycobacterial culture may take up to 6 weeks to yield results. Therefore, the diagnosis of tuberculous meningitis depends on the clinical manifestations of subacute to chronic meningitis with lymphocytic CSF and low CSF glucose levels. However, other forms of meningitis may mimic tuberculous meningitis. Certain patients with tuberculous meningitis may have CSF findings resembling aseptic meningitis. Several tests for the rapid diagnosis of tuberculous meningitis have been developed; all are based on examination of the CSF. These tests are considered indirect tests (usually measuring a product of the host response to his infection, such as adenosine deaminase(ADA), the radioactive bromide partition test and antibodies to the mycobacterial antigen) and direct tests usually measuring a product of the infecting organism, such as 3-(2'-ketohexyl) indoline, detecting of tuberculostearic acid (a component of the cell wall of M. tuberculosis), mycobacterial antigens or fragments of mycobacterial DNA by polymerase chain reaction (Zuger and Lowy, 1991)]. These methods except adenosine deaminase are too complicated or expensive for many laboratories. Adenosine deaminase (ADA) is an enzyme involved in purine catabolism. It is considered as an indicator of cell-mediated immunity and is found mainly in $\mathrm{T}$ lymphocytes (Sullivan et al, 1977).TBM is the severe form of extrapulmonary tuberculosis occurring in 7.0$12.0 \%$ of TB patients in developing countries with high rate of mortality due to delay in diagnosis and proper treatment (Rana et al 2004).In the absence of an early diagnosis and treatment, tuberculous meningitis is characterized by high mortality $(20-50 \%)$ and morbidity (20-30\%) (Kumar et al., 1999).

Adenosine deaminase (ADA) is an enzyme with principal biological activity in $\mathrm{T}$ lymphocytes. It is required for lymphocyte proliferation and differentiation. The enzyme activity is known to be elevated in certain infection where immunity is cell mediated like in CSF of TBM patients (Pias et al 1973; Ribera et al 1989; Prasad et al 1991). Various studies have been conducted demonstrating CSF ADA estimation as an enzymatic assay in diagnosis of Tuberculous meningitis and can differentiate TBM from normal subjects or other infectious meningitis.

\section{Pathogenesis of tuberculous meningitis:}

Many of the symptoms, signs, and sequelae of tuberculous meningitis (TBM) are the result of an immunologically directed inflammatory reaction to the infection. TBM develops in 2 steps. Mycobacterium tuberculosis bacilli enter the host by droplet inhalation, the initial point of infection being the alveolar macrophages. Localized infection escalates

1. Professor, Department of Medicine, Rangpur Medical College \& Hospital, Rangpur.

2. Registrar, Department of Medicine, Rangpur Medical College \& Hospital, Rangpur.

3. Consultant UHC, Rajnagar, Moulvibazar, Bangladesh.

4. Associate Professor, Department of Medicine, Dhaka Medical College \& Hospital, Dhaka.

Address of Correspondence: Dr. Devendra Nath Skarar, Professor, Department of Medicine, Rangpur Medical College \& Hospital, Rangpur, E-mail: prof.tariq@gmail.com

Bangladesh J Medicine 2014; 25 : 61-71 
within the lungs, with dissemination to the regional lymph nodes to produce the primary complex. During this stage, a short but significant bacteremia is present that can seed tubercle bacilli to other organs.In persons who develop TBM, bacilli seed to the meninges or brain parenchyma, resulting in the formation of small subpial or subependymal foci of metastatic caseous lesions. These are termed Rich foci, after the original pathologic studies of Rich and McCordick. Tuberculous pneumonia develops with heavier and more prolonged tuberculous bacteremia. Dissemination to the central nervous system (CNS) is more likely, particularly if miliary tuberculosis (TB) develops.

The second step in the development of TBM is an increase in size of a Rich focus until it ruptures into the subarachnoid space. The location of the expanding tubercle (ie, Rich focus) determines the type of CNS involvement. Tubercles rupturing into the subarachnoid space cause meningitis. Those deeper in the brain or spinal cord parenchyma cause tuberculomas or abscesses. While an abscess or hematoma can rupture into the ventricle, a Rich focus does not. A thick gelatinous exudate infiltrates the cortical or meningeal blood vessels, producing inflammation, obstruction, or infarction. Basal meningitis accounts for the frequent dysfunction of cranial nerves (CNs) III, VI, and VII, eventually leading to obstructive hydrocephalus from obstruction of basilar cisterns. Subsequent neurological pathology is produced by 3 general processes: adhesion formation, obliterative vasculitis, and encephalitis or myelitis (Tarakad 2011).

\section{Clinical feature of tuberculous meningitis}

\section{History}

Tuberculous meningitis (TBM) is difficult to diagnose, and a high index of suspicion is needed to make an early diagnosis. Inquire about the patient's medical and social history, including recent contact with patients with tuberculosis (TB). Elicit any known history of a positive result on the purified protein derivative test, especially a recent conversion. Determine if the patient has a history of immunosuppression from a known disease or from drug therapy, if the patient has a negative history for bacillus Calmette-Guérin (BCG) vaccination. Walker et al reported that $B C G$ vaccination is partially protective against TB meningitis; therefore, a history of $\mathrm{BCG}$ vaccination or the presence of a $\mathrm{BCG}$ vaccination scar affords some degree of reassurance when considering a diagnosis of TBM .In patients in whom TBM is suspected clinically, the diagnosis must be rigorously investigated; a history of $\mathrm{BCG}$ vaccination does not rule out the diagnosis.In an immunocompetent individual, central nervous system (CNS) TB usually takes the form of meningitis that causes an acute-to-subacute illness characterized by fever, headache, drowsiness, meningism, and confusion over a period of approximately 2-3 weeks. Usually, during the prodromal period, nonspecific symptoms are present, including fatigue, malaise, myalgia, and fever. The duration of presenting symptoms may vary from 1 day to 9 months, although $55 \%$ presented with symptoms of less than 2 weeks duration. (Tarakad 2011). Less frequent presentations include atypical febrile seizures in children, isolated cranial nerve $(\mathrm{CN})$ palsies, bilateral papilledema, and acute confusional state (Tarakad 2011).

\section{Physical Examination}

Careful general, systemic, and neurologic examinations are needed, looking especially for lymphadenopathy, papilledema, and tuberculomas during funduscopy and meningismus. Look also for a $B C G$ vaccination scar. Because BCG vaccination is partially protective against $\mathrm{TB}$ meningitis, the presence of a BCG vaccination scar affords some degree of reassurance when considering a diagnosis of TBM. Nevertheless, prior BCG vaccination does not rule out the diagnosis.

\section{Visual Findings}

Apart from papilledema, fundus examination occasionally reveals a retinal tuberculoma or a small grayish-white choroidal nodule, highly suggestive of TB. These lesions are believed to be more common in miliary TB than in other forms of TB. In children, fundus examination may reveal pallor of the disc. Examination may elicit visual impairment.

\section{Neurologic Findings}

Cranial neuropathies, most often involving CN VI, may be noted. CNs III, IV, VII, and, less commonly, CNs II, VIII, X, XI, and XII, also may be affected. Focal neurological deficits may include monoplegia, hemiplegia, aphasia, and tetraparesis. Tremor is the most common movement disorder seen in the course of TBM. In a smaller percentage of patients, abnormal movements, including choreoathetosis and hemiballismus, have been observed, more so in children than in adults. In addition, myoclonus and cerebellar dysfunction have been observed. Deep vascular lesions are more common among patients with movement disorders (Tarakad 2011).

\section{Other presentations of tuberculous meningitis}

1. Acute meningitis

2. Behavioural or intellectual disturbances without meningeal signs 
3. Encephalopathy

4. Seizures

5. Isolated cranial neuropathies

6. Stroke

7. Increased ICP

8. Recurrent serous or asceptic meningitis.

Overall Meningeal signs $70 \%$

Cranial palsy $25 \%$

Focal neurological findings $16-18 \%$

Active TB elsewhere - two thirds of TBM patients PPD +ve in $50 \%$

Active chest infection in some of the patients. (Ashok 2008)

\section{Complications of TBM:}

A. It untreated- nearly always fatal usually within 3-6 weeks of presentation.

B. It treated- Mortality rate $21 \%$ in imunocompetent patients $33 \%$ in HIV infected patients

C. Complications of untreated, late or incompletely treated CNS TB include:

Progressive hydrocephalus

Blindness caused by damage to the optic nerves and chiasm

SIADH

Tuberculoma associated edema and raised ICP

Vasculitis

Stroke

Arachnoiditis

Spinal cord atrophy

Syringomyelia

Abnormal CSF circulation or ventricular trapping due to arachnoid adhesions.

D. TBRM (tuberculous radiculomyelitis) is a complication of TBM that has been reported only rarely in the modern medical literature. It develops at various intervals after TBM, even in adequately treated patients after sterilization of the CSF. (Ashok 2008)

\section{Staging}

In 1948, the British Medical Research Council developed a method for staging the severity of the disease, as follows:

Stage I describes the early nonspecific symptoms and signs including apathy, irritability, headache, malaise, fever, anorexia, nausea, and vomiting, without any alteration in the level of consciousness

Stage II describes altered consciousness without coma or delirium but with minor focal neurological signs; symptoms and signs of meningism and meningitis are present, in addition to focal neurological deficits, isolated $\mathrm{CN}$ palsies, and abnormal involuntary movements

Stage III describes an advanced state with stupor or coma, dense neurological deficits, seizures, posturing, and/or abnormal movements ICP (Tarakad 2011).

\section{Diagnosis of TBM}

Tuberculous meningitis (TBM) continues to pose a diagnostic problem. A high index of clinical suspicion is absolutely essential. TBM should be a strong consideration when a patient presents with a clinical picture of meningoencephalitides, especially in highrisk groups, including persons with malnutrition, those who abuse alcohol or drugs, homeless persons, people in correctional facilities, residents of longterm care facilities, and patients with known HIV infection. Diagnostic confusion often exists between TBM and other meningoencephalitides, in particular partially treated meningitis.

\section{Approach Considerations}

The diagnosis of tuberculous meningitis (TBM) cannot be made or excluded on the basis of clinical findings. Tuberculin testing is of limited value. Variable natural history and accompanying clinical features of TBM hinder the diagnosis.

Spinal tap carries some risk of herniation of the medulla in any instance when intracranial pressure (ICP) is increased (eg, TBM), but if meningitis is suspected, the procedure must be performed regardless of the risk, using suitable precautions and obtaining informed consent before the procedure.

Computed tomography (CT) scanning and magnetic resonance imaging (MRI) lack specificity but help in monitoring complications that require neurosurgery.

Ziehl-Neelsen staining lacks sensitivity, and culture results are often too late to aid clinical judgment. Semiautomated radiometric culture systems, such as the Bactec 460, and automated continuously monitored systems have reduced culture times. Newer methods involving amplification of bacterial DNA by polymerase chain reaction (PCR) and comparable systems have not been assessed completely and may not be suitable for laboratories in developing countries with limited resources (Tarakad 2011).

\section{CSF Analysis}

\section{Cytology:}

The typical analysis of CSF from patients with CNS tuberculosis demonstrates a moderate lymphocytic 
pleocytosis, moderately elevated protein levels, and hypoglycorrachia (low glucose) (Sutlas et al 2003; Wong et al 1994). As such, the CSF proûle of CNS tuberculosis mimics the proûles of a large list of both infectious and noninfectious processes that affect the CNS. One series of non-HIV-infected adult cases of CNS tuberculosis in Turkey found CSF lymphocyte predominance in $85 \%$, neutrophil predominance in $15 \%$, high protein levels in $77 \%$, hypoglycorrachia in $67.2 \%$, and elevated opening pressure in $54 \%$ of patients (Sutlas et al 2003). Similar results among a series of pediatric cases were also noted (Yaramis et al 1998), and coinfection with HIV does not appear to alter the CSF proûle (Thwaites et al 2005). Although hypoglycorrachia is common in both bacterial meningitis and TBM, its presence may provide a convenient discriminating feature that distinguishes these etiologies from most other causes of meningoencephalitis, especially when considering the initiation of empirical antibiotics. The predominance of neutrophils in some cases likely represents an earlier stage of infection, which, over the course of days to weeks, will convert to a predominantly lymphocytic proûle (Kent et al 1993). Rarely, normal CSF ûndings have been identiûed in patients ultimately diagnosed with TBM (Daif et al 1992). It has been observed that the CSF can later brieûy switch to neutrophil predominance with antituberculosis therapy. It has been postulated that this "paradoxical response" is due to a hypersensitivity reaction related to the release of tubercular proteins during antituberculosis therapy and, in at least one retrospective series, was related to the development of tuberculomas on therapy (Sutlas et al 2003).

\section{Microbiological analysis of cerebrospinal fluid:} Identiûcation of AFB in the CSF through both smear and culture methods remains the most important and most widely available means to diagnose CNS tuberculosis. Despite its importance among the diagnostic methods used for CNS tuberculosis, traditional staining and culture remain relatively insensitive, most likely due to the typical paucity of AFB in a clinical case of CNS tuberculosis. Standard staining techniques using such stains as ZiehlNeelsen, Kinyoun, orauramine-rhodamine applied to CSF samples have been estimated to detect approximately $100 \mathrm{AFB} / \mathrm{ml}$ of CSF (Verdon et al 1996). As one could anticipate, the actual sensitivity of AFB staining of the CSF at any given laboratories highly variable and the inability of more recent series to reûect the yield that older series were able to achieve may reûect the loss of the art of AFB staining. Techniques to improve the sensitivity of AFB staining in the CSF were noted in several older studies. Some of the techniques included staining the clot that forms in standing CSF and spinning down the CSF sediment onto a slide for microscopic examination. The latter technique produced $91 \%$ sensitivity in 100 consecutive cases. In 1979, Kennedy and Fallon showed that staining multiple samples of CSF enhanced the sensitivity to $86 \%$ (Kennedy et al 1979).

Several case series also established CSF culture sensitivities of 25 to $70 \%$ (Naughten, E et al 1981). Samples from cisternal and ventricular CSF appear to have higher culture sensitivity than conventional (lumbar puncture) CSF samples (Verdon et al 1999). A recent study established that both CSF volume and duration of the microscopic evaluation are independently associated with bacteriological conûrmation of CNS tuberculosis, suggesting that a minimum of $6 \mathrm{ml}$ of CSF ûuid should be examined microscopically for a period of $30 \mathrm{~min}$ (Thwaites et al 2004).

\section{Molecular techniques for diagnosis of $\mathbf{M}$. tuberculosis}

The suboptimal and often delayed results from classical microbiological techniques traditionally used in the diagnosis of TBM underscore the need for a more rapid and accurate diagnostic method to facilitate early treatment. Several molecularly based techniques, often drawn from successful techniques used for the diagnosis of tuberculosis in respiratory specimens, have been evaluated for their applicability in the diagnosis of TBM. These techniques include commercially available nucleic acid ampliûcation (NAA) methods and other PCR-based methods, antibody detection, antigen detection, or chemical assays such as adenosine deaminase (ADA) and tuberculostearic acid measurements. Among the challenges in evaluating the utility of these molecularly based diagnostic techniques is the reliance on clinical diagnosis for entry criteria, the relatively low numbers of patients included in the studies, and the myriad of different techniques, targets, collection methods, and puriûcation modiûcations used, making the evaluation of tests that were not directly compared difûcult. Clarity will likely not occur until each method has been optimized for their speciûc target and procedure and then compared head-to-head.

\section{Adenosine deaminase (ADA)}

Adenosine deaminase catalyzes hydrolytic and irreversible deamination of dioxydenosine into dioxyinosine and of adenosine into inosine. This enzyme is widely distributed in human tissues in 
three forms soluble and inter convertible (small, intermediate, and large, in relation to its molecular weight). The activity of ADA is ten times greater in lymphocytic cells than in erythrocyets and in relation to the former is greater in T-lymphocytes than in Blymphocytes, and varies during T-cell differentiation, with significant increases of its level in immature or undifferentiated states (Piras et al, 1973).

Therefore, some authors consider ADA as a marker of cell-mediated immunity, with an increase in its serum level in different diseases. Regarding its main physiologic activity, ADA is related to lymphocytic differentiation and proliferation, showing a significant increase in its values during the mythogenic and antigenic response of lymphocytes (Hall, 1963). In additions Carson and Seegmiller (1976) found a restriction of lymphocytic blastogenesis following the activation of ADA inhibitors through biologic and nonclarified mechanisms, possibly connected with conversion of dioxyadenosine into dioxy-ATP, which, gathering selectively in lymphoytic cells, would cause its destruction by the inhibition of DNA synthesis. On the other hand, the congenital and genetically determined deficit of this enzyme with its autosomal recessive trait, described in over 30 cases, is usually associated with serve forms of combined immunodeficiency and is responsible for an increase in toxic nucleotides that prevent the differentiation or proliferation (or both) of T-lymphocytes and thus a normal immune function mediated by cells.

The raising of the levels of ADA activity under antigenic stimulation shows the importance of this enzyme in the rapid proliferation of cells in order to prevent the accumulation of toxic metabolites. Therefore, an increase in ADA activity is present in several circumstances: (1) in pleural, pericardic, and peritoneal effusions of a tuberculous nature, significantly when compared with neoplastic and metapneumonic (bacterial and viral) ones; (2) in pleural effusions that follow rheumatoid arthritis, and lymphoproliferative infections and, also, in empyema, although with levels usually smaller than in tuberculosis; (3) in tuberculous cerebrospinal fluid, where ADA values are significantly higher than in normal group and in other neurologic diseases; and (4) in peripheral lymphoblasts of patients with acute lymphoid leukemia (Baganha et al, 1990).

\section{Isoenzymes OF ADA:}

Human ADA exists in principal molecular from known as $\mathrm{ADA}_{1}, \mathrm{ADA}_{+\mathrm{CP}}$ and $\mathrm{ADA}_{2} \cdot \mathrm{ADA}_{1+\mathrm{CP}}$ are composed of two ADA molecules connected via a combining protein (Hirchhorn et al, 1980). $\mathrm{ADA}_{1}$ has equal affinities for adenosine and 2'-de-oxyadenosine and $\mathrm{ADA}_{2}$ has much greater affinity for adenosine. The $\mathrm{ADA}_{1}$ isoenzyme is found in all cells, especially in lymphocytes, while $\mathrm{ADA}_{2}$ isoenzyme is present mainly in monocytes and macrophages (Ungerer et al, 1992). The increase of intracellular $\mathrm{ADA}_{2}$ occurs when monocytes and macrophages are infected by intracellular microorganisms.

It is known that the ADA activity is high in tuberculous pleural effusions (Piras et al, 1978; Ocana et al, 1983). However, high ADA levels can also be found in pleural effusions secondary to pneumonia, empyema, and neoplasms especially those of hemopoietic origin, rheumatoid arthritis, and systemic lupus erythematosus. The high ADA activities in tuberculous pleural effusions are largely due to increased ADA (Gakis, 1996; Valdes et al, 1996). It is therefore important to determine the activities of ADA isoenzymes in a variety of pleural effusions. Increased $\mathrm{ADA}_{1}$ activity, on the other hand, is an indicator of para-pneumonic effusions, especially originating from the lymphocytes and monocytes. However, there may be little to be gained clinically in performing this additional difficult and costly step (Gorguner et al, 2000)

\section{Utility of ADA in diagnosis of TBM}

Several studies have been performed to evaluate the utility of ADA measurements in the CSF to improve the diagnosis of TBM (Blake et al 1982, Choi et al 2002, Coovadia et al 1986, Donald et al 1986,). The measured sensitivities and sensitivities range from 44 to $100 \%$ and 71 to $100 \%$, respectively (Table 2). While some of the studies showed statistically significant differentiation from aseptic meningitis and bacterial meningitis, several other studies could not demonstrate a distinction between TBM and bacterial meningitis by ADA alone (Donald et al 1986, Gambhir et al 1999), and in one study, ADA was not valuable in distinguishing TBM in patients with HIV infection Corral et al 2004. Additionally, standardized cutoffs of ADA values for the diagnosis of TBM have not been established, and the values used in the various studies ranged from 5.0 to $15 \mathrm{IU} /$ liter, making the practical use of this assay more difficult. CSF ADA measurements have been found to be useful in predicting poor neurological outcomes among pediatric TBM cases Jakka et al, 2005. It has also been established that isotype ADA2 is the major contributor to the total ADA seen in TBM (the same is true for bacterial meningitis) Schutte et al 2001. 
Table-I

Performance of immunoassays for TBM

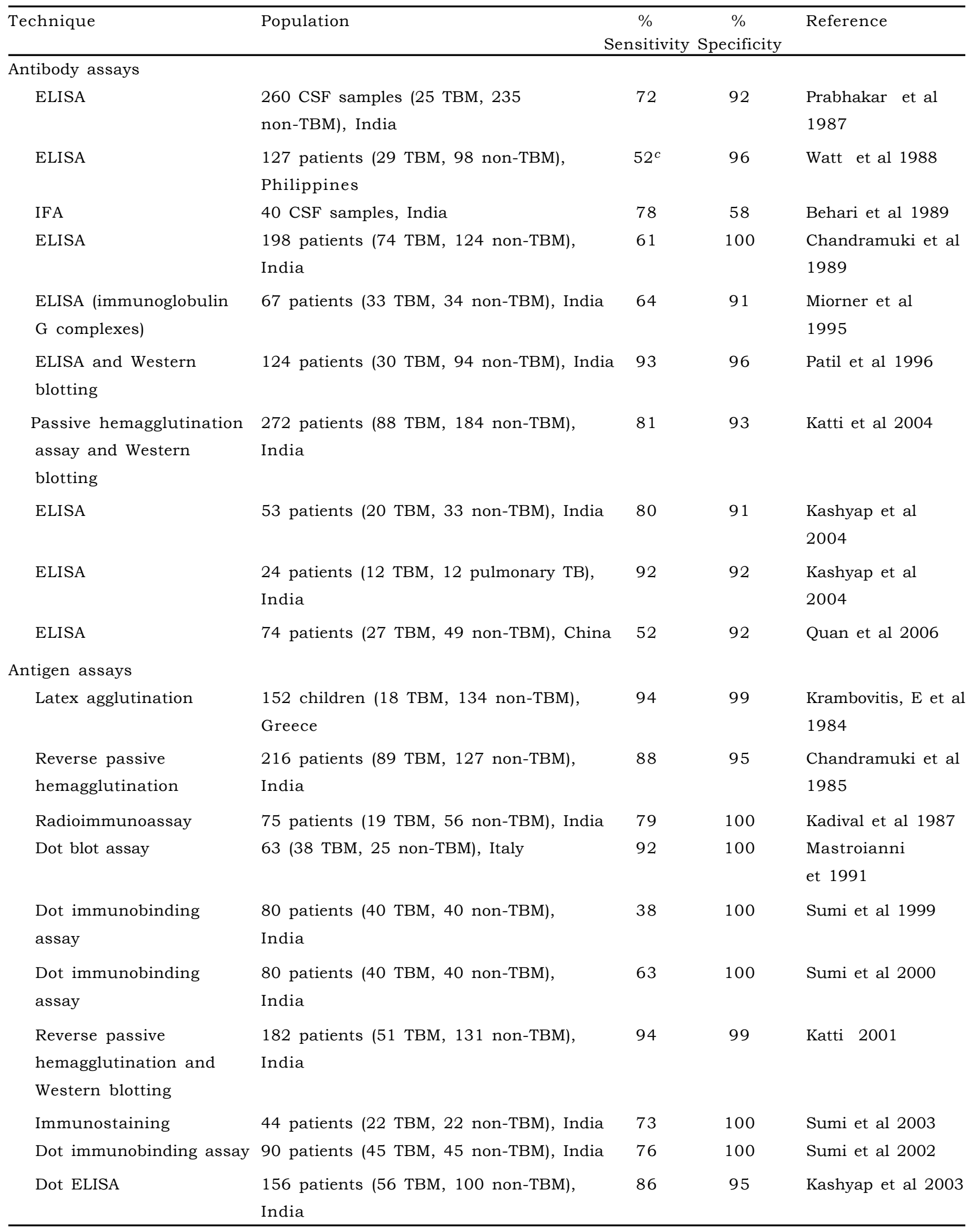


Table-II

Performance of biochemical assays for TBM

\begin{tabular}{|c|c|c|c|c|}
\hline Population & $\%$ & $\%$ Sensitivity & y\% Specificity & Reference \\
\hline \multicolumn{5}{|l|}{ ADA assays } \\
\hline Cutoff, > $6.0 \mathrm{IU} /$ liter & $\begin{array}{l}134 \mathrm{CSF} \text { samples ( } 24 \mathrm{TBM}, 110 \\
\text { non-TBM), South Africa }\end{array}$ & 92 & 98 & Blake et al 1982 \\
\hline Cutoff, $10.0 \mathrm{U} /$ liter & $\begin{array}{l}101 \text { pediatric patients ( } 38 \text { TBM, } 63 \\
\text { non-TBM), South Africa }\end{array}$ & 73 & 71 & Coovadia et al 1986 \\
\hline $\begin{array}{l}\text { Cutoff, } 5.0 \text { IU/liter vs } \\
\text { aseptic meningitis }\end{array}$ & $\begin{array}{l}97 \text { patients ( } 34 \text { TBM, } 63 \text { non-TBM), } \\
\text { South Africa }\end{array}$ & 70 & 99 & Donald et al 1986 \\
\hline Cutoff, $10.0 \mathrm{U} /$ liter vs & $\begin{array}{l}346 \text { adult CSF samples, Spain } \\
\text { aseptic meningitis }\end{array}$ & 48 & 100 & $\begin{array}{l}\text { Lopez-Cortes } \\
\text { et al } 1995\end{array}$ \\
\hline $\begin{array}{l}\text { Cutoff, } 5.0 \mathrm{IU} / \text { liter vs } \\
\text { pyogenic }\end{array}$ & $\begin{array}{l}35 \text { pediatric patients }(27 \mathrm{TBM} \text {, } \\
8 \text { pyogenic), India }\end{array}$ & 63 & 89 & Mishra et al 1995 \\
\hline Cutoff, $9.0 \mathrm{IU} /$ liter & $\begin{array}{l}119 \text { patients (14 TBM, } 105 \text { non-TBM), } \\
\text { Malaysia }\end{array}$ & 100 & 88 & Rohani et al 1995 \\
\hline Cutoff, $5.0 \mathrm{IU} /$ liter & $\begin{array}{l}66 \text { pediatric patients ( } 27 \text { TBM, } 39 \\
\text { non-TBM), India }\end{array}$ & 89 & 92 & Mishra et al 1996 \\
\hline Cutoff, 8.0 IU/liter & 60 patients (36 TBM, 24 non-TBM), India & 44 & 75 & Gambhir et al 1999 \\
\hline Cutoff, $7.0 \mathrm{U} /$ liter vs viral & $\begin{array}{l}182 \text { patients ( } 36 \text { TBM, } 9 \text { pyogenic, } 130 \\
\text { viral, } 7 \text { cryptococcal), South Korea }\end{array}$ & $\begin{array}{c}83 \\
\text { (vs viral) }\end{array}$ & $\begin{array}{l}95 \\
\text { (vs viral) }\end{array}$ & Choi et al 2002 \\
\hline $\begin{array}{l}\text { Cutoff, } 10.0 \mathrm{U} / \text { liter vs } \\
\text { pyogenic }\end{array}$ & & $\begin{array}{c}58 \text { (vs } \\
\text { pyogenic) }\end{array}$ & $\begin{array}{c}89 \text { (vs } \\
\text { pyogenic) }\end{array}$ & \\
\hline Cutoff, $11.39 \mathrm{U} /$ liter/min & $\begin{array}{l}281 \text { patients ( } 171 \text { culture confirmed, } \\
41 \text { pyogenic, } 19 \text { viral, } 104 \text { controls), } \\
\text { India }\end{array}$ & 82 & 83 & Kashyap et al 2006 \\
\hline \multicolumn{5}{|l|}{ Tuberculostearic acid assays } \\
\hline $\begin{array}{l}\text { Gas chromatography } \\
\text { and mass spectrometry }\end{array}$ & $\begin{array}{l}13 \text { culture confirmed cases; ( } 9 \text { suspected } \\
\text { cases); } 87 \text { negative controls }\end{array}$ & $100(89)$ & 99 & French et al 1987 \\
\hline Gas-liquid chromatography & $\begin{array}{l}41 \text { culture confirmed cases (Cairo, Egypt); } \\
75 \text { clinical cases (United States, Canada) }\end{array}$ & 95 & 91 & Brooks et al 1990 \\
\hline
\end{tabular}

\section{Treatment of TBM}

Antibiotic therapy and adjunctive corticosteroid therapy:

The best antimicrobial agents in the treatment of TBM include isoniazid (INH), rifampin (RIF), pyrazinamide (PZA), and streptomycin (SM), all of which enter cerebrospinal fluid (CSF) readily in the presence of meningeal inflammation. Ethambutol is less effective in meningeal disease unless used in high doses. The second-line drugs include ethionamide, cycloserine, ofloxacin, and para aminosalicylic acid (PAS). INH, RIF, and PZA are bactericidal. RIF and SM achieve optimal CSF levels only when the meninges are inflamed. Usually, intrathecal drugs are not necessary. Treatment is best started with INH, RIF, and PZA. The addition of a fourth drug is left to the choice of the local physicians and their experience, with little evidence to support the use of one over the other. Evidence concerning the duration of treatment is conflicting. The duration of conventional therapy is 6-9 months, although some investigators still recommend as many as 24 months of therapy. Studies have shown that young children with TBM can be treated safely for 6 months with high doses of anti-TB agents without overt hepatotoxicity and with a low risk of relapse. Children should be treated for 12 months with combination antibiotic therapy and initial adjunctive corticosteroids. Twelve months is probably a conservative estimate of the time required for bacterial cure. The rationale behind the use of 
adjuvant corticosteroids lies in reducing the harmful effects of inflammation as the antibiotics kill the organisms.

The use of corticosteroids in adults is controversial; they may be indicated in the presence of increased intracranial pressure (ICP), altered consciousness, focal neurological findings, spinal block, and tuberculous encephalopathy. Treatment of tuberculoma consists of high-dose steroids and continuation of antituberculous therapy, often for a prolonged course. In tuberculous radiculomyelitis (TBRM), as in other forms of paradoxical reactions to anti-TB treatment, evidence shows that steroid treatment might have a beneficial effect (Tarakad 2011).

To ascertain the immediate and underlying causes of death in adults who died in hospital with an antemortem diagnosis of tuberculosis, Martinson et al, in their autopsy studies, demonstrated disseminated, extensive tuberculosis associated with advanced HIV disease. Severe bacterial infections, including salmonellosis, were the leading comorbidity, suggesting that hospitalized HIV-infected adults in whom tuberculosis is suspected may benefit from broad-spectrum antibiotic therapy.

Since uveitis is often treated with immunosuppressive and corticosteroid therapy, such treatment may have catastrophic consequences if patients with tuberculous granulomatous uveitis were not properly diagnosed and managed (Tarakad 2011).

\section{Role of Surgery}

Surgical procedures in tuberculous meningitis are primarily related to treatment of hydrocephalus. Nonobstructive hydrocephalus may be managed medically with serial lumbar punctures, diuretic agents like furosemide and acetozolamide along with antituberculous drugs but obstructive hydrocephalus requires external ventricular drainage followed by shunt surgery. Shunt Surgery is considered safe even in the presence of active disease and can bring considerable improvement in sensorium. Early shunting with drugs may improve therapeutic outcome (Thwaites et al, 2002).Effective antituberculous therapy has reduced the need for surgical excision of tuberculomas as most can now be managed medically. Even tuberculomas which increase in size on medical therapy are monitored for at least two months before contemplating surgery. (Shankar et al, 1991)

\section{Prognosis and outcomes OF TBM:}

1. Overall mortality in tuberculous meningitis is about $30 \%$. Mortality highest in those with low
Glasgow Coma Scale score or higher medical research council (MRC) stage at presentation(table 3). Mortality is also greater in those in whom therapy is delayed or interrupted.

\section{Table-III}

Outcome of tuberculous meningitis based on MRC stage at presentation:

\begin{tabular}{llcc}
\hline Stage & Clinical Features & Mortality & Sequelae \\
\hline I & $\begin{array}{l}\text { Meningeal signs but } \\
\text { normal mental status } \\
\text { and no focal neurologic } \\
\text { findings }\end{array}$ & $<10 \%$ & Minimal \\
& $\begin{array}{l}\text { Confusion or focal } \\
\text { neurologic findings }\end{array}$ & $20 \%-30 \%$ & $40 \%$ \\
III & $\begin{array}{l}\text { Stupor or coma with } \\
\text { hemiplegia or paraplegia } \\
\text { MRC, medical research }\end{array}$ & & \\
& council. & & \\
\hline
\end{tabular}

2. Neurologic sequelae include hemiparesis or hemiplegia, paraplegia, visual or hearing loss, cognitive changes. Neurologic sequelae are also highest in those with low Glasgow Coma Scale score or higher MRC stage at presentation and in those who present with focal neurologic findings (table -III).

3. Hydrocephalus may require external ventricular drainage (EVD) or a permanent shunt (Samuels, 2004).

\section{Conclusion}

On the basis of present result when ADA interpreted together with clinical signs and symptoms and other laboratory tests, it can be a useful adjunctive rapid test for the diagnosis of TBM. The estimation of ADA activity in CSF is therefore serves as relatively simple, inexpensive and reliable tool in the diagnosis of TBM and management especially when other clinical laboratory tests are negative within sensitive limit.This study along with Gautam et al.and kashyap et al studies reemphasized that CSF-ADA level measurement can be used as a good, rapid and reliable laboratory test for diagnosing tuberculous meningitis at least in high prevalence and in cases of the incidence of tuberculosis in low income regions.

\section{References:}

1. Ashok Verma,2008..Infections of the nervous system.In:WG Bradely, R B Darott,GM Fenidel,J Jancovic(eds).Neurology in Clinical Practice;5th edn, New York,Elsevier:p 1420. 
2. Baganha MF, Pego Alice,Lima MA,Graspar EV,Phram B and Cordeiro AR,1990. 'Serum and pleural adenosine deaminase, correlation with lymphocytic populations', Chest.Vol.97,pp605-610

3. Behari M, M Raj, G K Ahuja and Shrinivas, 1989. 'Soluble antigen fluorescent antibody test in the serodiagnosis of tuberculous meningitis', J. Assoc. Phys. India.vol. 37,pp499-501.

4. Brooks J B, M I Daneshvar, R L Haberberger and I A Mikhail, 1990. 'Rapid diagnosis of tuberculous meningitis by frequency-pulsed electroncapture gasliquid chromatography detection of carboxylic acids in cerebrospinal fluid', J. Clin. Microbiol.vol. 28,pp989-997.

5. Carson A and Seegmiller JE,1976. 'Effect of Adenosine deaminase inhibition upon human lymphocyte blastogenesis', JnClin Invest.Vol.57, pp274-82.

6. Chandramuki A, G H Bothamley, P J Brennan and J Ivanyi, 1989. 'Levels of antibody to defined antigens of Mycobacterium tuberculosis in tuberculous meningitis" J. Clin. Microbiol. vol.27,pp821-825.

7. Choi SH, Kim YS and Bae IG,2002. 'The possible role of cerebrospinal fluid adenosine deaminase activity in the diagnosis of tuberculous meningitis in adults', Clin Neurol Neurosurg. vol.104,pp5-10.

8. Chotmongkol V, Jitpimolmard $\mathrm{S}$ and Thavornpitak Y,1996. 'Corticosteroid in tuberculous meningitis', J Med Assoc Thai.vol. 79,pp83-90.

9. Coovadia YM, Dawood A and Ellis ME,1986. ' Evaluation of ADA activity and antibodies to $M$. tuberculosis antigen 5 in $\mathrm{CSF}$ and the radioactive bromide partition test for the early diagnosis of TBM'. Arch Dis Child.vol.61,pp428-35.

10. Daif A, Obeid T, Yaqub B, and AbdulJabbar M. 1992. 'Unusual presentation of tuberculous meningitis', Clin. Neurol. Neurosurg.vol. 94,pp1-5.

11. Donald P R, C Malan, V Walt, and J F Schoeman, 1986. 'The simultaneous determination of cerebrospinal fluid and plasma adenosine deaminase activity as a diagnostic aid in tuberculous meningitis', S. Afr. Med. J.vol. 69,pp505-507.

12. French G L, R Teoh, C Y Chan, M J Humphries, S W Cheung and G O'Mahony, 1987. 'Diagnosis of tuberculous meningitis by detection of tuberculostearic acid in cerebrospinal fluid', Lancet ii.pp117-119.

13. Gakis C,1996. 'Adenosine deaminase (ADA) isoenzymes ADA1 and ADA2:Diagnostic and biological role',Eur Respir J.vol.9,pp632-3

14. Garcia-Monco JC, Marra CM, editor, 1999. CNS Tuberculosis. Neurologic Clinics.vol.17(4),pp737-760.

15. Gambhir IS, Mehta M, Singh DS and Khanna HD.1999. 'Evaluation of CSF-adenosine deaminase activity in tubercular meningitis', $J$ Assoc physician India.vol.47,pp192-194.

16. Gorguner M,Cerci M and Gorguner I,2000. 'Determination of adenosine deaminase activity and its isoenzymes for diagnosis of pleural effusions', Respirology. vol 5, pp321-324

17. Hall JG,1963. 'Adenosine deaminase activity in lymphoid cells during antibody production', Aust $J$ Exp Biol Med Sci.vol.41,pp93-7

18. Hirachhorn R, Ratech H,1980. 'Isozymes of adenoeinedeaminase', Curr Top Biol Med Res vol.4,pp131-57.

19. Jakka S, S Veena, A R Rao and M Eisenhut, 2005. 'Cerebrospinal fluid adenosine deaminase levels and adverse neurological outcome in pediatric tuberculous meningitis', Infection. vol.33,pp264266.

20. Kadival G V, A M Samuel, T B Mazarelo and S D Chaparas, 1987. 'Radioimmunoassay for detecting Mycobacterium tuberculosis antigen in cerebrospinal fluids of patients with tuberculous meningitis', $J$. Infect. Dis.vol.155,pp608-611.

21. Kashyap R S, R P Kainthla, R M Satpute, N H Chandak, H J Purohit, G M Taori et al,2004. 'Demonstration of IgG antibodies to $30 \mathrm{Kd}$ protein antigen in CSF for diagnosis of tuberculous meningitis by antibody-capturing ELISA', Neurol. India. vol. 52,pp359-362.

22. Katti M K, 2004. 'Pathogenesis, diagnosis, treatment, and outcome aspects of cerebral tuberculosis', Med. Sci. Monit. vol.10,pp215-229.

23. Kennedy D H, and R J Fallon, 1979. 'Tuberculous meningitis', JAMA. vol.241,pp264-268.

24. Kent S J, S M Crowe, A Yung, C R Lucas and A M Mijch,1993. 'Tuberculous meningitis: a 30-year review', Clin. Infect. Dis.vol. 17,pp987-994.

25. Krambovitis E, M B McIllmurray, P E Lock, W Hendrickse and H Holzel, 1984. 'Rapid diagnosis of tuberculous meningitis by latex particle agglutination', Lancet ii.pp1229-1231.

26. Kumar R, Singh SN, Kohlin,1999. 'A diagnostic rule for tuberculosis meningitis', Archieves of the diseae of childhood.vol.81,pp221-4

27. Lopez-Cortes L F, M Cruz-Ruiz, J Gomez-Mateos, D Jimenez-Hernandez, E Jimenez-Mejias, J Pachon et al,1995. 'Adenosine deaminase activity in the CSF of patients with aseptic meningitis: utility in the diagnosis of tuberculous meningitis or neurobrucellosis', Clin. Infect. Dis. vol.20,pp525-530.

28. Mastroianni C M, V Vullo, F Paoletti, A P Massetti, $\mathrm{F}$ Sorice and S.Delia, 1991. 'Detection of mycobacterial antigen by dot blot assay in the cerebrospinal fluid of patients with tuberculous meningitis', J. Infect. vol.22,pp106-107. 
29. Miorner H, U Sjobring, $P$ Nayak and A Chandramuki, 1995. 'Diagnosis of tuberculous meningitis: a comparative analysis of 3 immunoassays, an immune complex assay and the polymerase chain reaction', Tuber. Lung Dis. vol. 76,pp381-386.

30. Mishra O P, V Loiwal, Z Ali, G Nath, L Chandra, and B K Das, 1995. 'Cerebrospinal fluid adenosine deaminase activity and $\mathrm{C}$-reactive protein in tuberculous and partially treated bacterial meningitis', Indian Pediatr. vol.32,pp886-889.

31. Misra U K, J Kalita, M Srivastava and S K Mandal, 1996. 'Prognosis of tuberculous meningitis: a multivariate analysis', J. Neurol. Sci.vol.137,pp57-61.

32. Naughten E, A M Weindling, R Newton, and B D Bower, 1981. 'Tuberculous meningitis in children. Recent experience in two English centres', Lancet ii.pp973-975.

33. Ocana I, Martinez-Vazquez JM, Ribera E, Segura RM and Pascual C,1986. 'Adenosine deaminase activity in the diagnosis of lymphocytic pleural effusions of tuberculous, neoplastic and lymphomatous origin', Tubercle.vol.67,pp141-5

34. Patil S A, M Gourie-Devi, J R Chaudhuri, and A Chandramuki, 1996. 'Identification of antibody responses to Mycobacterium tuberculosis antigens in the CSF of tuberculous meningitis patients by Western blotting', Clin. Immunol. Immunopathol. vol.81,pp35-40.

35. Piras MA, Gakis C,1973. 'Cerebrospinal fluid adenosine deaminase activity in tuberculousmeningitis',Enzyme.vol.14,pp311-16.

36. Prabhakar S and Thussu A,1997. 'CNS Tuberculosis', Neurology India. vol.45,pp132-40.

37. Prasad R. Kumar A and Khanna BK, 1991. 'Adenosine deaminase activity in cerebrospinal fluid for diagnosis of tuberculous meningitis', Indian $J$ Tub. vol.38,pp 99-102

38. Quan C, C Z Lu, J Qiao, B G Xiao and X Li, 2006. 'Comparative evaluation of early diagnosis of tuberculous meningitis by different assays', J. Clin. Microbiol.vol.44,pp3160-3166.

39. Rana SV, Singhal RK, Singh K and Kumar L,2004, 'Adenosine deaminase levels in cerebrospinal fluid as a diagnostic test for tuberculous meningitis in children', Indian J Clinbiochem.vol.19,pp 5-9.

40. Ribera E, Martinez-Vazquez JM, Ocana I, Segura RM and Pascual C,1987, 'Activity of adenosine deaminase in cerebrospinal fluid for the diagnosis and follow-up of tuberculous meningitis in adults', $J$ Infect Dis,vol. 155,pp 603-7.

41. Rohani MY, Y M Cheong, and J M Rani, 1995, 'The use of adenosine deaminase activity as a biochemical marker for the diagnosis of tuberculous meningitis', Malays. J. Pathol.vol. 17,pp67-71.

42. Samuels Martin A,2004.Manual of neurologic therapeutics, seventh edition, Philadelphia, Lippincot Williams \& Wilkins,p525.

43. Schutte C M, J P Ungerer, $\mathrm{H}$ du Plessis and $\mathrm{C} \mathrm{H}$ van der Meyden. 2001, 'Significance of cerebrospinal fluid adenosine deaminase isoenzymes in tuberculous (TB) meningitis', J. Clin. Lab. Anal.vol. 15,pp236-238.

44. Shankar P, Manjunath N, Mohan KK, Prasad K, Behari M, Sriniwas et al,1991, 'Rapid diagnosis of tuberculosis meningitis by polymerase chainreaction', Lancet.vol. 337,pp 3-7.

45. Sumi M G, A Mathai, C Sarada, and V V Radhakrishnan, 1999, 'Rapid diagnosis of tuberculous meningitis by a dot immunobinding assay to detect mycobacterial antigen in cerebrospinal fluid specimens', J. Clin. Microbiol.vol.37,pp3925-3927.

46. Sumi M G, A Mathai, S Reuben, C Sarada, V V Radhakrishnan, R Indulakshmi et al,2002, 'A comparative evaluation of dot immunobinding assay (Dot-Iba) and polymerase chain reaction (PCR) for the laboratory diagnosis of tuberculous meningitis', Diagn. Microbiol. Infect. Dis. vol.42,pp35-38.

47. Sumi M G, M Annamma, C Sarada, and V V Radhakrishnan, 2000, 'Rapid diagnosis of tuberculous meningitis by a dot-immunobinding assay', Acta Neurol. Scand.vol. 101,pp61-64.

48. Sullivan JL, Osborne WR and Wedgewood RJ,1977, 'Adenosine deaminase activity in lymphocytes', $\mathrm{Br} \mathrm{J}$ Haematol.vol.37,pp 157-8.

49. Sutlas P N, A Unal, H Forta, S Senol, and D Kirbas, 2003, 'Tuberculous meningitis in adults: review of 61 cases', Infection.vol. 31,pp387-391.

50. Tarakad S Ramachandran,2011, Tuberculous Meningitis; Chief Editor: Karen L Roos; Medscape; http://emedicine.medscape.com/article/ 1166190

51. Thwaites G E, D B Nguyen, H D Nguyen, T Q Hoang, $\mathrm{T}$ T Do, T C Nguyen et al,2004, 'Dexamethasone for the treatment of tuberculous meningitis in adolescents and adults', N. Engl. J. Med. vol.351,pp1741-1751

52. Thwaites G E, N D Bang, N H Dung, H T Quy, D T $\mathrm{T}$ Oanh, T T Chau et al, 2005, "The inûuence of HIV infection on clinical presentation, response to treatment, and outcome in adults with tuberculous meningitis', J. Infect. Dis.vol.192,pp2134-2141.

53. Ungerer JPJ, Oosthuizen Bissbort SH, Vermark WJH,1992, 'Serum adenosine deaminase: Isoenzymes and diagnostic application', Clin Chem.vol.38,pp.1322-6. 
54. Valdes L, Jose Es, Alvarez D, Valle JM,1996, 'Adenosine deaminase (ADA) isoenzyme analysis in pleural effusions:diagnostic role and relevance to the origin of increased ADA in tubercuolous pleurisy',Eur Respir J. vol 9,pp747-751

55. Verdon R, S Chevret, J P Laissy, and M. Wolff, 1996, 'Tuberculous meningitis in adults: review of 48 cases', Clin. Infect. Dis.vol. 22,pp982-988.

56. WalterJ, Koroshetz, and Morton N Swartz, 2008. Chronic and recurrent meningitis, In:Anthony SFauci, DennisL Kasper,Dan L Longo(eds).Harrinson's Principles of Internal Medicine, 17 th edn, New york,MacGraw-Hill. vol.2,no.376,pp 2642-44.

57. Watt, G., G. Zaraspe, S. Bautista, and L. W. Laughlin, 1988, 'Rapid diagnosis of tuberculous meningitis by using an enzyme-linked immunosorbent assay to detect mycobacterial antigen and antibody in cerebrospinal fluid', J. Infect. Dis.vol.158,pp681-686.

58. WHO reports 2003, Global TB control, surveillance, planning, financing; communicable diseases, WHO, Geneva p18.

59. Wong G W, S J Oppenheimer, W Poon and R Leung,1994, 'Intracranial tuberculoma and hydrocephalus developing during treatment of tuberculous meningitis', J. Trop. Med. Hyg. vol.97, pp236-238.

60. Yaramis A, F Gurkan, M Elevli, M Soker, K Haspolat, G Kirbas et al,1998, 'Central nervous system tuberculosis in children: a review of 214 cases', Pediatrics. vol.102, ppE 49.

61. Zuger A, Lowy FD,1991.Tuberculosis of the central nervous system. In: Scheld WM, Whitley RJ, Durack DT, eds. Infections of the central nervous system. New York: Raven Press, pp425-56. 